\title{
Effect of live body weight and method of synchronization on ovulation, pregnancy rate and embryo and fetal loss in buffalo heifers
}

\author{
Luigi Esposito $^{1}$ (D), Donato de Nicola ${ }^{1}$ (D), Anna Balestrieri² ${ }^{2}$, Georgios Petrovas ${ }^{1}$ (D), Francesca Licitra ${ }^{3}$ (D), \\ Angela Salzano $^{1 *}$ (D), Gianluca Neglia ${ }^{1}$ (D) \\ ${ }^{1}$ Università degli Studi di Napoli "Federico II", Dipartimento di Medicina Veterinaria e Produzioni Animali, Napoli, Italy \\ ${ }^{2}$ Istituto Zooprofilattico Sperimentale del Mezzogiorno, Portici, Napoli, Italy \\ ${ }^{3}$ Istituto Zooprofilattico Sperimentale della Sicilia, Ragusa, Italy
}

\begin{abstract}
This study aimed to assess the influence of live body weight (LBW) and age on reproductive performance in buffalo heifers synchronized by different treatments. The study was carried out on 146 Mediterranean buffalo heifers (mean age $25.3 \pm 13.4$ months, LBW $424 \pm 47 \mathrm{~kg}$ ), divided into 2 homogeneous groups and synchronized by Ovsynch-TAI Program (OVS; $\mathrm{n}=72$ ) or double prostaglandin administered 12 days apart (PGF; $\mathrm{n}=74$ ). All the buffaloes were inseminated twice and follicle dimensions and ovulation rate (OR) were assessed by ultrasound 24 and 48 h post-insemination. Pregnancy was assessed on day 25, 45 and 90 post-insemination and the incidence of late embryonic (LEM) and fetal (FM) mortality were respectively recorded. Data were analyzed by ANOVA, Chi-square test and multiple logistic regression. The LBW was significantly $(\mathrm{P}<0.05)$ higher in inseminated animals, compared to those that did not respond to the treatments $(450.0 \pm 3.2$ vs. $423.2 \pm 9.6 \mathrm{~kg}$ in inseminated and not inseminated heifers, respectively). Total OR was similar between groups, although OR at $24 \mathrm{~h}$ tended to be higher $(\mathrm{P}=0.06)$ in OVS $(86.7$ vs. $72.9 \%$ in OVS and PGF, respectively). A $(\mathrm{P}<0.01)$ higher LBW was observed in ovulated heifers of PGF, while no differences were recorded in OVS. LBW affected OR (odds ratio = 1,032; $\mathrm{P}<0.05$ ) only in PGF, while no effects were recorded in OVS. Total pregnancy rate, LEM and FM were similar between groups. In conclusion, the LBW would be considered before including buffalo heifers in a synchronization program and both synchronization treatments can be useful.
\end{abstract}

Keywords: pubescent buffalo, synchronization, weight score.

\section{Introduction}

In buffalo species the optimization of breeding techniques in Italy allowed to reduce the age at first calving from about 45 months to less than 30 months in 30 years (Bhatti et al., 2007). The onset of puberty and, consequently, the age at first calving, is deeply affected by several factors, such as management, together with genotype and climate (Campanile et al., 2009). However, one of the main aspects influencing the reaching of puberty is the live body weight

*Corresponding author: angela.salzano@unina.it

Received: January 29, 2019

Accepted: July 11, 2019
(LBW; Campanile et al., 2009). An anticipation of puberty has been observed in both Egyptian (El Nouty, 1971) and Mediterranean buffaloes (Campanile et al., 2001) that showed a daily weight gain after weaning of 0.45 and $0.55 \mathrm{~kg}$, respectively. A reduction of the generation interval can be obtained anticipating the age at first calving and by the utilization of artificial insemination (AI). Recently, several synchronization protocols have been developed in buffalo, doubling the efficiency of AI (25-50\% pregnancy rate) over a period of approximately two decades (Zicarelli et al., 1997; Neglia et al., 2015). However, the majority of studies has been primarily performed in adult buffaloes (Neglia et al., 2016; Monteiro et al., 2018), while few trials were carried out in heifers (Carvalho et al., 2017; Neglia et al., 2018). In cyclic buffalo heifers with normal Corpus Luteum (CL) function, the response to estrus synchronization by Prostaglandin $\mathrm{F}_{2 \alpha}$ $\left(\mathrm{PGF}_{2 \alpha}\right.$; Zicarelli et al., 1997) or Ovsynch-Timed Artificial Insemination (O-TAI) program (Neglia et al., 2018), is comparable to the response observed in cattle. However, at present, no information are available on the relationships between the body weight and reproductive performance in buffalo heifers treated by different synchronization protocols. Therefore, the aims of this study were: i) to assess the influence of LBW on reproductive performance in buffalo heifers; and ii) to evaluate if the synchronization by double $\mathrm{PGF}_{2 \alpha}$ or O-TAI program may affect pregnancy rate in buffalo heifers.

\section{Methods}

Animals

The investigation was carried out in accordance with EU Directive 2010/63/EU and the Animal Ethics Committee of the University of Naples, Federico II (Permit number 2013/010858). The study was carried out on 146 Italian Mediterranean buffalo heifers, previously chosen (see below), with a mean age of $25.3 \pm 13.4$ months and a mean LBW of $424 \pm 47 \mathrm{~kg}$, between February and March 2017. To ensure the best welfare conditions, buffalo heifers were maintained in open yards that allowed $10 \mathrm{~m}^{2}$ for animal and received a total daily mixed ration consisting in $8 \mathrm{~kg}$ of dry matter, $0.85 \mathrm{UFL} / \mathrm{kg}$ dry matter, $13 \%$ crude protein, $18 \%$ starch and $44 \%$ NDF. Twenty and ten days before the start of the trial, the animals underwent ultrasound examination with a portable Sonoace Pico (Medison, Seoul, South Korea) equipped with a $10 \mathrm{MHz}$ linear transducer for trans rectal 
examination. Only heifers in good health, without any abnormalities of the genital tract and with the presence of a $\mathrm{CL}$ in at least one examination were included in the study. Furthermore, in correspondence with the second ultrasound examination, all the animals were weighed. Only the animals with a LBW $>270 \mathrm{~kg}(\mathrm{n}=146)$ were chosen. This because puberty is related to the age at first oestrus, (at about 16.5-19.0 months) and to the LBW (at around 340-360 kg) (Borghese et al., 1994).

\section{Estrus synchronization treatments and AI}

The selected heifers were divided into two homogeneous groups, according to LBW and age. Heifers in OVS $(n=72)$ underwent synchronization of ovulation by O-TAI Program (Neglia et al., 2016). Heifers in PGF $(\mathrm{n}=74)$ underwent synchronization by a double $\mathrm{PGF}_{2 \alpha}$ analogue (Dinoprost, 25 mg; Dinolytic ${ }^{\circledR}$, Zoetis, Rome, Italy) injection on day 0 and 12 , at a random day of the cycle. AI were performed by the same operator and each buffalo was inseminated twice: at 16 and 40 hours after the second injection of GnRH in OVS and at 60 and 84 hours after the last $\mathrm{PGF}_{2 \alpha}$ in PGF (Neglia et al., 2008). Because of the low intensity of estrous behavior in buffaloes (Ohashi, 1994), the heifers were palpated per rectum to assess the estrous status (tonic uterus in presence or absence of vaginal mucus discharge) and underwent ultrasound examination to record preovulatory follicle. The ovulation rate was assessed by ultrasound in each group, 24 and 48 hours after the first insemination. Frozen/thawed semen of two bulls of proven fertility was utilized in the AI program in both groups. Finally, the body condition score was assessed on the day of AI, by using a 1 to 9 scale (Wagner et al., 1988).

\section{Pregnancy assessment}

Twenty-five days after AI, buffaloes underwent trans rectal ultrasonography to assess embryonic development and the heartbeat. Pregnancy diagnosis was confirmed on day 45 and 90 after AI: heifers pregnant on day 25 but not on day 45 were considered to have undergone late embryonic mortality. Similarly, buffaloes pregnant on day 45 but not on day 90 were considered to have undergone fetal mortality.

\section{Statistical analysis}

Differences in ovulation rate after 24 and 48 hours after the $1^{\text {st }} \mathrm{AI}$ and pregnancy between treatments were assessed by Chi-square test. Differences in age, LBW, BCS, pregnancy rate, LEM and FM between treatments were assessed by ANOVA. Two separate logistic regression models were estimated to assess the ovulation rate at different time within each treatment with respect to the LBW. Pregnancy outcome was evaluated by a logistic regression second order model using LBW and treatment as independent variables. All statistics were performed using the IBM SPSS Statistics for Windows, version 20.0" program (IBM, 2011).

\section{Results}

Eleven animals did not respond to the synchronization treatments and were excluded from the trial. A total of $92.5 \%$ synchronization rate was recorded, without any difference between the two synchronization treatments (93.1 vs. 91.9\% in OVS and PGF, respectively). LBW was $(\mathrm{P}<0.05)$ higher in animals that were inseminated, compared to those that did not respond to the synchronization treatment $(450.0 \pm 3.2$ vs. $423.2 \pm 9.6 \mathrm{~kg}$ in inseminated and not inseminated heifers, respectively), whereas a similar age was recorded ( $796.5 \pm 9.0$ vs. $789.7 \pm 40.7$ days in inseminated and not inseminated heifers, respectively). No differences were recorded in preovulatory follicle dimensions between OVS and PGF, neither on the day of TAI ( $1.27 \pm 0.02$ vs. $1.32 \pm 0.03 \mathrm{~cm}$, in OVS and PGF, respectively) nor at $24 \mathrm{~h}(1.49 \pm 0.06$ vs. $1.50 \pm 0.04 \mathrm{~cm}$, in OVS and B, respectively). Ovulated buffaloes showed a significantly $(\mathrm{P}<0.05)$ higher LBW compared to not-ovulated counterparts (Table 1) regardless of the treatment, and in particular in the PGF Groupand a similar total ovulation rate was recorded between OVS and PGF. However, within each treatment, only ovulated heifers of PGF showed a significantly $(\mathrm{P}<0.01)$ higher $\mathrm{LBW}$ and age compared to those not ovulated, whereas no differences were recorded in animals synchronized by O-TAI Program (Table 1). Neither the LBW nor the age affected ovulation rate at 24 and 48 hours after insemination (data not shown). However, the ovulation rate recorded in OVS at $24 \mathrm{~h}$ tended to be higher $(\mathrm{P}=0.06)$ compared to that recorded in $\mathrm{PGF}$ (86.7 vs. $72.9 \%$ in OVS and PGF, respectively). The multiple logistic regression analysis showed that ovulation rate tended to be influenced by LBW, independently of the treatment (odds ratio $=1,030 ; \mathrm{P}=0.08$ ). If only heifers in PGF were considered, ovulation rate was significantly affected by $\mathrm{LBW}$ (odds ratio $=1,032 ; \mathrm{P}<0.05$ ), while no effects were recorded in OVS. Similarly, ovulation rate at $24 \mathrm{~h}$ was significantly influenced by LBW only in PGF (odds ratio $=1,033 ; \mathrm{P}<0.01$ ), but no effects were observed in OVS. No influence of LBW was observed for the ovulation rate at $48 \mathrm{~h}$. Data on pregnancy rate are reported in Table 1. If only ovulated animals were considered, LBW tended to be higher $(\mathrm{P}=0.08)$ in pregnant heifers compared to not pregnant counterparts ( $457.2 \pm 4.2$ vs. $445.7 \pm 5.3$, in pregnant and not pregnant heifers, respectively), whereas a similar age was recorded. No differences were found between OVS and PGF (Table 1) in terms of pregnancy rate and a similar live body weight and age were recorded between pregnant and not pregnant heifers within each treatment. However, a significantly higher pregnancy rate was recorded in heifers ovulated after $48 \mathrm{~h}$ in PGF $(12 / 16 ; 75 \%)$ vs OVS $(3 / 8 ; 37.5 \%)$. The regression logistic analysis for pregnancy, did not assess any influence of LBW or age on pregnancy. Finally, no differences were recorded for BCS in both pregnant and not pregnant heifers in both groups (7.2 \pm 0.2 vs. $7.3 \pm 0.2$, in pregnant and not pregnant heifers of OVS, respectively and $7.1 \pm 0.2$ vs. $7.2 \pm 0.2$, in pregnant and not pregnant heifers of PGF, respectively). 
Table 1. Effect of live body weight (LBW) on synchronization, ovulation and pregnancy rate and on embryo and fetal loss in buffalo heifers synchronized with Ovsynch-TAI Program (OVS) and double prostaglandin (PGF).

\begin{tabular}{|c|c|c|c|c|c|}
\hline \multirow{2}{*}{ Synchronization rate } & \multicolumn{2}{|c|}{ OVS } & \multicolumn{2}{|c|}{ PGF } & \multirow[t]{2}{*}{$\begin{array}{c}\text { Statistical } \\
\text { Significance }\end{array}$} \\
\hline & & & & & \\
\hline$\%$ & Yes & No & Yes & No & \\
\hline (n) & $(67)$ & $(5)$ & $(68)$ & $(6)$ & \\
\hline LBW & $457.1 \pm 4.4$ & $434.0 \pm 21.2$ & $449.4 .7^{\mathrm{a}}$ & $414.2 \pm 2.2^{\mathrm{b}}$ & $P=0.04$ \\
\hline Ovulation rate & Yes & No & Yes & No & \\
\hline$\%$ & 60 & 7 & 59 & 9 & \\
\hline (n) & $(89.6)$ & $(10.4)$ & $(86.8)$ & $(13.2)$ & \\
\hline LBW & $450.8 \pm 4.5$ & $454.0 \pm 19.2$ & $454.4 \pm 5.0^{\mathrm{a}}$ & $413.2 \pm 6.7^{\mathrm{b}}$ & $\mathrm{P}=0.03$ \\
\hline Pregnancy Rate (90 d) & Yes & No & Yes & No & \\
\hline$\%$ & 47.8 & 52.2 & 57.4 & 42.6 & \\
\hline (n) & $(32)$ & $(35)$ & (39) & (29) & \\
\hline LBW & $456.3 \pm 5.7$ & $446.3 \pm 6.6$ & $458.0 \pm 6.1$ & $436.8 \pm 6.9$ & \\
\hline Embryo Loss & Yes & No & Yes & No & \\
\hline$\%$ & 15.0 & 85.0 & 7.1 & 92.9 & \\
\hline (n) & (6) & $(34)$ & (3) & (39) & \\
\hline LBW & $427.8 \pm 12.5$ & $455.1 \pm 5.5$ & $453.3 \pm 6.9$ & $458.0 \pm 6.1$ & \\
\hline Fetal Loss & Yes & No & Yes & No & \\
\hline$\%$ & 5.9 & 94.1 & 0.0 & 100.0 & \\
\hline (n) & (2) & (32) & $(0)$ & (39) & \\
\hline LBW & $434.5 \pm 13.5$ & $456.3 \pm 5.7$ & & $458.0 \pm 6.1$ & \\
\hline $\begin{array}{l}\text { Total embryo and } \\
\text { fetal loss }\end{array}$ & Yes & No & Yes & No & \\
\hline$\%$ & 20.9 & 79.1 & 7.1 & 92.9 & \\
\hline (n) & (8) & (32) & (3) & (39) & \\
\hline LBW & $429.5 \pm 9.6$ & $456.3 \pm 5.7$ & $453.3 \pm 6.9$ & $458.0 \pm 6.1$ & \\
\hline
\end{tabular}

\section{Discussion}

This study aimed to assess the influence of LBW on reproductive efficiency in buffalo heifers. An optimal management in this category of subjects influences the age at first calving and allows to anticipate the start of their productive life, reducing the generational interval and favoring the genetic improvement of the herd. Accordingly, reproductive development in heifers and the attainment of puberty are determined primarily by nutrition from the time of weaning (Campanile et al., 2001). Some studies performed in buffalo (Campanile et al., 2001, 2009), demonstrated that post-weaning weight gain may influence reproductive performance in heifers and the LBW on the day of insemination further affects reproduction, particularly when different protocols of synchronization are applied. In our study, LBW significantly influenced either the response to the synchronization treatment and the ovulation rate. In Mediterranean Italian buffaloes, different studies showed an age at first oestrus, stated as the first blood $\mathrm{P}_{4}$ rise at a value over $1 \mathrm{ng} / \mathrm{ml}$, at about 16.5-19.0 months of age and at around 340-360 kg of body weight (Borghese et al., 1994). Cyclic ovarian activity, with a $P_{4}$ value $>1 \mathrm{ng} / \mathrm{ml}$ at about a ten-day interval was achieved at 20.7 months of age and at a body weight of 380-390 kg (Borghese et al., 1994). On these bases, in our study all the heifers with LBW lower than $370 \mathrm{~kg}$ were excluded from the trial. It is worth pointing out that the influence of LBW was only observed in PGF. Synchronization by double prostaglandin needs a regular cyclic activity of the animals, as demonstrated by the evidence that anoestrus or prepubertal subjects are not responsive (Stevenson and Pursley, 1994). After the onset of puberty, LH decreased at a level similar to that of 4 months before puberty and a positive correlation between LH and body weight was found during the prepubertal period (Haldar and Prakash, 2006). On the contrary, the LBW did not affect the ovulation rate in animals synchronized by O-TAI Program. The latter is largely applied in both buffalo (Neglia et al., 2016; Sharma et al., 2017), and bovine species (Pursley et al., 1995; Carvalho et al., 2015), because of its feasibility and practical and economic advantages. The ovulation that occurs following exogenous $\mathrm{GnRH}$ administration is due to the presence of a follicle with ovulatory capability. In cattle, a follicle requires on average 7 to 10 days to go through the stages of emergency, deviance and dominance and then reaches the preovulatory stage or encounters atresia (Ginther et al., 1989). In buffalo the deviation phase, and hence the acquisition of LH receptors, is reached at a mean diameter of $0.75 \mathrm{~cm}$ (Baruselli et al., 2001). The ovulation rate recorded at $24 \mathrm{~h}$ tended to be higher in heifers of OVS compared to those of PGF. It is known that the last GnRH of the O-TAI treatment aims to induce an endogenous LH surge that is responsible for the synchronization of ovulation (Pursley et al., 1995). 
On the contrary, treatment by double prostaglandin is based on CL regression, a consequent decrease of circulating progesterone that in turn causes an increase of GnRH and LH pulse frequency, that can act on the preovulatory follicle. Therefore, in this case the ovulation is not induced and it is dependent from the maturation and the oestradiol levels of the preovulatory follicle (Kastelic and Ginther, 1991). In a previous trial carried out in adult buffaloes synchronized by O-TAI Program, it was demonstrated that the LH surge occurs about 1 hour after GnRH injection (Campanile et al., 2008). On the other hand, with the double PGF2 $\alpha$ protocol LH surge occurs naturally and GnRH peak and hence the ovulation may be slightly delayed. In fact, in heifers ovulated at $48 \mathrm{~h}$ a significantly higher pregnancy rate was recorded compared to Ovsynch-treated buffaloes. In any case, no differences were observed between the two synchronization protocols in terms of pregnancy rate, suggesting that both protocols can be used in buffalo heifers. The treatment by double prostaglandin resulted in a $10 \%$ more pregnancy rate, despite of the low number of ovulated buffaloes at $24 \mathrm{~h}$ and the requirement of two AI. An improvement in this protocol may be obtained by administrating a GnRH two days later the last prostaglandin in order to synchronize the ovulation rate at $24 \mathrm{~h}$. On the contrary, the O-TAI Program is characterized by a short duration and by the possibility of reducing the number of inseminations allowing economic advantages. In any case, a key point is the selection of the heifers, that would reach a reasonable weight and ovarian cyclicity.

\section{References}

Baruselli PS, Amaral R, Barufi FB, Valentim R, Marques MO. Lecirelin and Buserelin (gonadotrophin releasing hormone agonists) are equally effective for fixed time insemination in buffalo.. Braz J Vet Res Anim Sci. 2001;38(3):142-5. http://dx.doi.org/10.1590/S1413-95962001000300009.

Bhatti SA, Sarwar M, Khan MS, Hussain SMI. Reducing the age at first calving through nutritional manipulations in dairy buffaloes and cows: a review. Pak Vet J. 2007;27(1):42-7.

Borghese A, Terzano GM, Barile VL, Annichiarico G, Allegrini $\mathrm{S}$, Zicarelli L. Pubertà e mantenimento dell'attività ciclica ovarica nella bufala. Agricoltura e Ricerca. 1994;153:5-16.

Campanile G, Di Palo R, Gasparrini B, D’Occhio MJ, Zicarelli L. Effects of early management system and subsequent diet on growth and conception in maiden buffalo heifers. Livest Prod Sci. 2001;71(2-3):183-91. http://dx.doi.org/10.1016/ S0301-6226(01)00190-7.

Campanile G, Vecchio D, Baruselli PS, Di Palo R, Neglia G, D'Occhio MJ. Understanding the function of the corpus luteum and the onset of puberty in buffalo. Perspect Agric Vet Sci Nutr Nat Resour. 2009;4(2):1-8. http://dx.doi. org/10.1079/PAVSNNR20094002.

Campanile G, Vecchio D, Neglia G, Di Palo R, Prandi A, D'Occhio MJ. Progesterone and pregnancy status of buffaloes treated with a GNRH agonist. Livest Sci. 2008;115(23):242-8. http://dx.doi.org/10.1016/j.livsci.2007.08.001.

Carvalho NAT, Soares JG, Souza DC, Maio JRG, Sales JNS, Martins B Jr, Macari RC, D’Occhio MJ, Baruselli PS. Ovulation synchronization with estradiol benzoate or GnRH in a timed artificial insemination protocol in buffalo cows and heifers during the nonbreeding season. Theriogenology. 2017;87:333-8. http://dx.doi.org/10.1016/j. theriogenology.2016.09.006. PMid:27743689.

Carvalho PD, Fuenzalida MJ, Ricci A, Souza AH, Barletta RV, Wiltbank MC, Fricke PM. Modifications to Ovsynch improve fertility during resynchronization: evaluation of presynchronization with gonadotropin-releasing hormone $6 \mathrm{~d}$ before initiation of Ovsynch and addition of a second prostaglandin F2 $\alpha$ treatment. J Dairy Sci. 2015;98(12):874152. http://dx.doi.org/10.3168/jds.2015-9719. PMid:26433420.

El Nouty FE. Effect of different feeding systems before and after weaning on age at puberty and at first conception in buffalo heifers [thesis]. Cairo: Faculty of Agriculture, Ain Shams, University of Cairo; 1971.

Ginther OJ, Kastelic JP, Knopf L. Composition and characteristics of follicular waves during the bovine estrous cycle. Anim Reprod Sci. 1989;20(3):187-200. http://dx.doi. org/10.1016/0378-4320(89)90084-5.

Haldar A, Prakash BS. Growth hormone-releasing factor (GRF) induced growth hormone advances puberty in female buffaloes. Anim Reprod Sci. 2006;92(3-4):25467. http://dx.doi.org/10.1016/j.anireprosci.2005.06.002. PMid:16011881.

International Business Machines Corporation - IBM. IBM SPSS Statistics for Windows, version 20.0. Armonk: IBM; 2011.

Kastelic JP, Ginther OJ. Factors affecting the origin ofthe ovulatory follicle in heifers with induced luteolysis. Anim Reprod Sci. 1991;26(1-2):13-24. http://dx.doi. org/10.1016/0378-4320(91)90062-5.

Monteiro BM, Souza DC, Vasconcellos GSFM, Carvalho NAT, Baruselli PS. Effect of season on dairy buffalo reproductive performance when using P4/E2/eCG-based fixed-time artificial insemination management. Theriogenology. 2018;119:27581. http://dx.doi.org/10.1016/j.theriogenology.2018.07.004. PMid:30064074.

Neglia G, Capuano M, Balestrieri A, Cimmino R, Iannaccone F, Palumbo F, Presicce GA, Campanile G. Effect of consecutive re-synchronization protocols on pregnancy rate in buffalo (Bubalus bubalis) heifers out of the breeding season. Theriogenology. 2018;113:120-6. http://dx.doi. org/10.1016/j.theriogenology.2018.01.020. PMid:29494837.

Neglia G, Gasparrini B, Salzano A, Vecchio D, De Carlo E, Cimmino R, Balestrieri A, D’Occhio MJ, Campanile G. Relationship between the ovarian follicular response at the start of an Ovsynch-TAI program and pregnancy outcome in the Mediterranean river buffalo. Theriogenology. 
2016;86(9):2328-33. http://dx.doi.org/10.1016/j. theriogenology.2016.07.027. PMid:27577986.

Neglia G, Natale A, Esposito G, Salzillo F, Adinolfi L, Campanile G, Francillo M, Zicarelli L. Effect of prostaglandin F2 $\alpha$ at the time of AI on progesterone levels and pregnancy rate in synchronized Italian Mediterranean buffaloes. Theriogenology. 2008;69(8):953-60. http://dx.doi. org/10.1016/j.theriogenology.2008.01.008. PMid:18346780.

Neglia G, Restucci B, Russo M, Vecchio D, Gasparrini B, Prandi A, Di Palo R, D’Occhio MJ, Campanile G. Early development and function of the corpus luteum and relationship to pregnancy in the buffalo. Theriogenology. 2015;83(6):95967. http://dx.doi.org/10.1016/j.theriogenology.2014.11.035. PMid:25543155.

Ohashi OM. Estrus detection in buffalo cow. Buffalo J. 1994;10(2):61-4.

Pursley JR, Mee MO, Wiltbank MC. Synchronization of ovulation in dairy cows using PGF $2 \alpha$ and GnRH. Theriogenology. 1995;44(7):915-23. http://dx.doi. org/10.1016/0093-691X(95)00279-H. PMid:16727787.
Sharma RK, Phulia SK, Jerome A, Singh I. Ovsynch Plus protocol improves ovarian response in anovular Murrah buffaloes in low-breeding season. Reprod Domest Anim. 2017;52(6):1030-5. http://dx.doi.org/10.1111/rda.13020. PMid:28691349.

Stevenson JS, Pursley JR. Use of milk progesterone and prostaglandin F2 $\alpha$ in a scheduled artificial insemination program. J Dairy Sci. 1994;77(6):1755-60. http://dx.doi. org/10.3168/jds.S0022-0302(94)77116-2. PMid:8083432.

Wagner JJ, Lusby KS, Oltjen JW, Rakestraw J, Wettemann RP, Walters LE. Carcass composition in mature Hereford cows: estimatioand effect on daily metabolizable energy requirement during winter. J Anim Sci. 1988;66(3):603-12. http://dx.doi.org/10.2527/jas1988.663603x. PMid:3378920.

Zicarelli L, Esposito L, Campanile G, Di Palo R, Armstrong DT. Effects of using vasectomized bulls in artificial insemination practice on the reproductive efficiency of Italian buffalo cows. Anim Reprod Sci. 1997;47(3):17180. http://dx.doi.org/10.1016/S0378-4320(97)00008-0. PMid:9329858.

\section{Financial support: None.}

Author contributions: LE: Conceptualization, Writing - original draft, Writing - review \& editing; DN: Investigation, Data curation; AB: Methodology, Project administration; GP: Investigation, Data curation; FL: Resourcer, Validation; AS: Formal Analysis, Writing - original draft, Writing - review \& editing; GN: Conceptualization, Funding acquisition, Supervision.

Conflicts of interest: The authors have no conflict of interest to declare. 